\title{
Small Boat Fishing in Hawaii: A Random Utility Model of Ramp and Ocean Destinations $^{1}$
}

\author{
Timothy C. Haab, Professor \\ Agricultural, Environmental and Development Economics \\ The Ohio State University \\ Columbus, $\mathrm{OH} 43210$ \\ Haab.1@osu.edu \\ Marcia Hamilton, Economist \\ Western Pacific Fishery Management Council \\ Mailing Address \\ 2609 Doris $\mathrm{Pl}$. \\ Honolulu HI 96822 \\ Marcia.Hamilton@noaa.gov \\ Kenneth E. McConnell, Professor \\ Agricultural and Resource Economics \\ University of Maryland \\ College Park, MD 20742 \\ KMcconnell@arec.umd.edu
}

\begin{abstract}
This paper investigates small boat fishing on the island of Oahu, Hawaii. We develop a model in which anglers choose to launch their trailered boats, as well as their ocean destination. The model allows us to study spatial aspects of small boat fishing, including the benefits and costs of attributes of different regions of the ocean, such as fish aggregating devices. Second, it allows us to understand the effects of limiting access to various fishing areas.
\end{abstract}

Short title: Small Boat Fishing in Hawaii

Key words: random utility models, recreational fishing

JEL classification codes: Q2, Q22, Q26, Q51 


\section{Introduction}

Spatial allocation of fishing effort is a critical choice both for anglers and for policy makers. For the commercial fishermen, the choice of fishing effort is perhaps the most important short-run decision that a vessel owner or captain can make. Recent research by Holland and Sutinen (2000), Smith (2005), and Mistiaen and Strand (2000) models the short-run spatial allocation of effort for commercial fishing trips that often take several weeks. For policy makers, area closures or area restrictions are frequently used to control fishing effort and such research could inform their policy choices. Spatial regulations are occasionally used to limit the effects of fisheries on endangered species, as is studied in Curtis and Hicks (2000). The general issues are summarized in Smith (2000). ${ }^{2}$ The development of marine sanctuaries is a form of spatial regulation.

The study of spatial choices by large commercial vessels has developed into a central theme in fisheries economics. It is motivated by the frequent use of spatial regulations and the desire to understand supply decisions. However, the need to understand ocean destinations goes beyond the study of commercial fishing vessels. Area closures are sometimes made for the purpose of improving opportunities for smaller vessels or for conserving the target stocks. Without a sense of choice of ocean destination, such area controls may not be effective. In some cases, small vessels in sufficient numbers can harvest at levels that significantly reduce stock abundance. Planning for marine sanctuaries necessitates understanding the choice of location by small boat fisheries. Current restrictions on fishing in Hawaii include a ban on longline fishing in coastal waters and local regulations on small vessels. For example, the shore area from Kapiolani Park to Diamond Head is closed to small boat fishing for certain periods each year. ${ }^{3}$ 
In this article, we estimate a spatially oriented model of small boat fishing site choice for anglers from the island of Oahu, Hawaii. The fishing occurs in the Pacific Ocean from boats that are trailered to launch ramps or occasionally kept at marinas. The determination of fishing location involves two choices: where to launch the boat and where to fish. We develop a random utility model to explain these choices.

By estimating the model of ocean choice, as well as ramp choice, we acquire an understanding of a variety of spatially related issues. As noted, when regulations relate to areas, either as closures or as a means of enhancing one fishing sector at the expense of another, it is useful to know how these regulations restrict the choices that anglers make. Further, some public activities, such as the deployment of fish aggregation devices (FADs), have distinct locational dimensions. FADs located in a wind shadow of Oahu are entirely different from FADs on the windward side of the island. We can learn more by developing models of location choice. Because choices typically depend on the attributes of the locations, model estimation reveals the implicit values of attributes of such locations. We specify the model so that anglers differ in their targets and equipment, and we can show how policies might influence anglers differently.

Most studies of recreational fishing deal with shore sites or simply the choice of where to launch. ${ }^{4}$ This paper is among the few attempts to understand choices of on-the-water fishing locations by recreational anglers. Milon (1988) investigates the choices of artificial marine habitat by recreational anglers in southeast Florida. The angers are modeled as choosing between nearby coastal fishing sites and offshore sites located near the continental shelf. Given the selection of the offshore sites, anglers then choose between natural sites and artificial sites created from derelict vessels. Understanding these choices is especially important as 
competition for fish stocks by commercial and recreational anglers increases.

\section{The Survey and Data}

To investigate the behavioral choices of small boat anglers in Hawaii, we used a phone survey of Hawaii small boat anglers. ${ }^{5}$ The sample of anglers is from a list of registered boats in Hawaii in 1997 and 1998. The eligible population amounts to about 6,600 boat owners in Hawaii whose vessels would permit them to fish. From this, a random sample of 468 anglers was drawn. ${ }^{6}$ The anglers fish for diverse motives. Some are purely recreational, many sell their catch, and others engage in cooperative giving, expecting something in return in the future. Pure commercial activity is rare among the respondents, though not to be ruled out completely.

Small boat anglers typically trailer their boats, although a small subset of the interviewed anglers dock their boat at marinas. Fishing choices are made on the basis of information shared among anglers, knowledge of the fishery, and current information about weather. For purposes of modeling the spatial choice on the water, we use destinations delineated by the Hawaii Division of Aquatic Resources (HDAR). For management purposes, this agency divides the ocean surrounding the islands into roughly concentric zones. Each concentric zone is then subdivided into 'pie-shaped' sub-zones (which we call statistical grids, or grids for short). These grids serve as the destination 'sites' for angling choice (see figure 1). The anglers know some of the grids by numbers, and even if they don't, they typically have a clear idea of where they plan to go based on weather and information about fishing. To get to the right area of the ocean they choose an appropriate launch ramp. ${ }^{7}$ 


\section{Explaining Choices}

We model the anglers' choices among alternatives as trading off ramp and ocean destination attributes and costs. We estimate the model based on the last trip taken by the angler, for which

complete information was gathered. ${ }^{8}$ Other things equal, anglers would like to catch more fish, experience relatively calm days, have more inexpensive trips, and enjoy greater ease launching their boats. We state these motives formally when we set up the econometric model.

To explain ramp and destination choices, the survey collected data on angler choices of launch ramp and on-water fishing destination. Ramp-specific characteristics, such as travel costs and travel time to each ramp, convenience amenities at the ramps (parking spaces, etc.), and wind conditions at the ramp serve as determinants of launch ramp choice for anglers who trailer their boats. Characteristics of grid sites - the on-water destinations - such as the ocean travel costs, a proxy for fish stock density for anglers that target specific species, size of the site, and number of $\mathrm{FADs}^{9}$ within each grid determine the on-water destination for each angler. Anglerspecific characteristics also influence choice of ramps and ocean destinations.

Based on angler interviews and personal communication with officials knowledgeable of boating conditions on Oahu, we identify 12 locations as viable ramps for launching a trailered boat on Oahu (see table 1). In two cases, due either to geographic proximity or closure of a ramp, ramps were combined into a single "ramp" for model estimation purposes (Hawaii Kai/Maunalua Bay and Waianae/Pokai Bay). An additional choice category is considered for moored boats ("ramp" 13 in table 1). That is, respondents who moor their boats at a dock or marina do not trailer their boats and hence do not choose launch ramps. Instead they are 
assumed to choose the mooring site as their point of launch. Table 1 gives a brief description of the launch ramps and some of their characteristics.

Weather patterns, especially the critical elements of wind speed and direction, strongly influence the choice of fishing location. High winds make it difficult to launch boats and render fishing unpleasant. Fishing areas and ramps that are on the leeward side would typically be on the south and west coasts when the wind is out of the north and east during periods of trade winds on Oahu. The presence of trade winds presents undesirable conditions for small boats launched from ramps with north and northeast exposure. Table 1 reports the ramps exposed to trade winds. ${ }^{10}$

The final column of table 1 reports the percentage of sampled anglers reporting each ramp as their launch site on their last trip. Almost half of the anglers launched from either Waianae or Heeia-Kea on their most recent trips. The launch ramp at Waianae is a very popular site during the yellowfin tuna summer run. Yellowfin runs are common off Waianae during July and August. Discussions with anglers also indicate that the ramps at Kailua and Kahana are exposed to high winds and are, in general, difficult for launching and hence are less desirable ramps. We explain the choice sets for anglers below.

The 34 statistical areas visited by sampled anglers are often well known by the fishermen, but vary greatly in size. For estimation purposes, this exogenous difference in size of the destination sites is captured by including a measure of the water surface area of each grid site (in square-kilometers). Figure 1 shows the grid sites. The sites that ring Oahu, grids $400-409$, represent what will be termed coastal grids. The distinction between coastal and non-coastal grid sites is important because anglers with smaller boats (boat length $<20$ feet) tend to choose to fish in coastal grid sites, while those with larger boats (boat length $\geq 20$ feet) are more willing to 
venture into non-coastal grid sites. When the grids and ramps are chosen jointly, there are 442 potential ramp-grid combinations for each angler to choose from (13 ramps $\times 34$ grids), although in practice the number is less. The choice set for individuals, explained in detail in the section on model specification and estimation, is modified based on additional information about the individual.

The size of the grid area is a determinant of fishing location, other things equal, simply because it is likely to encompass other attractive attributes that are unmeasured. In addition to the size of the grid site, the best measure of its fishing attractiveness is expected catch of individual species. We do not observe catch by small boats, and there are no historical records of small boat catch that would serve as a proxy for expected catch. Instead, we look for a measure of the determinants of catching fish. An ideal measure of the potential for catching fish is a measure of stock abundance or density. We use data on sales by species from commercial vessels that sell their catch at the United Auction in Honolulu. Sales (in weight) are recorded by the grid areas, date, and species. The data are historical and reflect the harvests of the commercial vessels, some of them quite large. The pounds of fish sold is a proxy for stock densities of a grid, not expected catch. Locations with higher landings are likely to be more productive, making the grid site more attractive to commercial and recreational fishermen.

At a number of grid sites, the Division of Aquatic Resources has placed FADs. These devices are anchored in specific locations and serve to attract smaller fish species which, in turn, attract larger species. The FADs give anglers a focal point for their fishing efforts. As such, it is expected that the number of FADs in a grid area will increase the probability of visitation.

Several characteristics of respondents or their equipment are important for modeling their behavior on trips. As modeled by Bockstael, Strand, and Hanemann (1987), the degree of 
attachment to the labor force influences an individual's allocation of time between work and leisure, as well as the opportunity cost of time. Seventy-three percent of the respondents (340) are employed full time, while 21 percent (97) are retired. Only 3\% of respondents (14) reported being currently unemployed. Boat length may also influence ramp choice because larger boats cost considerably more to haul. The average length of boats owned by respondents is 18.3 feet, with a minimum length of 7 feet and a maximum length of 42 feet. The average boat length is 17.6 feet for those who trailer their boat. Moored boats average 23.7 feet.

\section{Modeling Small Boat Choices}

Anglers choose their fishing sites based, in part, on proxies for stock density, the weather, driving distances, and ocean cruising distances. We assume that the attributes that attract fishing effort to different parts of the ocean are similar, whether anglers have commercial motives or are purely recreational. Estimation of the parameters that describe behavior and determine the economic value of various changes begins with the specification of the utility function. For this purpose, we adopt the conditional logit random utility model as applied to recreational site choice (see Haab and McConnell [2002]). The indirect utility function for angler $j$, leaving from harbor or ramp $r$, going to ocean destination (grid) $a$, takes the form of:

$$
u_{r a}(j)=v_{r a}(j)+\varepsilon_{r a j}=\mathbf{x}_{r a j} \beta+\varepsilon_{r a},
$$

where $v_{r a j}$ is the deterministic component of utility; $\mathbf{x}_{r a j}$ is a vector of explanatory variables that 
can vary by individual, ramp and site (or any sub-combination); $\boldsymbol{\beta}$ is a vector of parameters; and $\varepsilon_{r a j}$ is the random component of preferences. The variables may also be time-dependent in the sense that the characteristics of the ramp or destination may vary seasonally. They reflect the weather or other site-specific attributes that one expects to prevail at that time of year, but not the precise daily conditions of the site. In the conditional logit model each $r, a$ alternative is modelled as a separate choice. The nested logit model, which might seem a more compelling approach, is not satisfactory because many of the same ocean sites can be reached from a variety of ramps.

The indirect utility function for individual $j$ is specified as:

$$
\begin{aligned}
v_{r a}(j) & =\beta_{1}\left(c_{r j}+c_{r a j}\right)+\beta_{2} \cdot \delta_{w j} \cdot t_{r j}+\beta_{3} \cdot \delta_{s j} \cdot t_{r j} \\
& +\sum_{f=1}^{4} \beta_{4 f} q_{a f} \delta_{f j}+\delta_{n j} \sum_{f=1}^{4} \beta_{5 f} q_{a f} \\
& +\beta_{6} \cdot K M_{a^{\prime}}^{2}+\beta_{7} \cdot W_{r}+\beta_{8} \cdot F_{a}+\beta_{9} \cdot P_{r}+\beta_{10} \cdot \delta_{b j} \cdot \delta_{c a} \\
& +\beta_{11} \cdot\left(1-\delta_{b j}\right) \cdot \delta_{c a}++\beta_{12} \cdot \delta_{W I r} \cdot \delta_{4 j}+\beta_{13} \cdot \delta_{K I r}+\beta_{14} \cdot \delta_{K A r} .
\end{aligned}
$$

The full set of variables for the $j^{\text {th }}$ respondent includes:

$$
\begin{aligned}
& c_{r j}=\text { travel cost from home to ramp or harbor } r \\
& c_{r a j}=\text { travel cost by boat from ramp or harbor } r \text { to area } a ; \\
& t_{r j}=\text { travel time from home to ramp or harbor } r ; \\
& q_{a f}=\text { pounds of species group } f \text { sold from area } a ; \\
& K M_{a}^{2}=\text { surface area of grid site } a \text { in kilometers squared; } \\
& P_{r}=\text { number of designated parking spaces at ramp r; } \\
& F_{a}=\text { number of fish aggregating devices (FADs) in area } a .
\end{aligned}
$$


The following are indicator variables that take the value 1 when true and 0 otherwise:

$\delta_{w j}=1$ if $j$ does not work flexible hours;

$\delta_{s j}=1$ if $j$ is retired;

$\delta_{f j}=1$ if $j$ targets species $f ;$

$\delta_{n j}=1$ if $j$ targets no species;

$\delta_{b j}=1$ if $j$ has a boat of length greater than or equal to 20 feet;

$\delta_{c a}=1$ if grid $a$ is a coastal grid;

$\delta_{W I r}=1$ if ramp $r$ is Waianae and zero otherwise;

$\delta_{4 j}=1$ if $j$ took their last trip in period July-August;

$\delta_{K I r}=1$ if the ramp is Kailua;

$\delta_{K A r}=1$ if the ramp is Kahana.

$W_{r}$ is a dummy variable that equals 1 if the ramp has a northern or eastern exposure during trade wind months (January-April).

With the exception of wind exposure and variables that do not change temporally, the variables are defined for the specific two-month period during which the angler took the trip.

Targeting of species is determined during the phone interview. Respondents reported which among the four species groups they were seeking. Four species groups are aggregated across the major fisheries in Hawaii: Billfish, Bottomfish, Other Pelagic, and Tuna. The terms $\sum_{f=1}^{4} \beta_{4 f} q_{a f} \delta_{f j}$ and $\delta_{n j} \sum_{f=1}^{4} \beta_{5 f} q_{a f}$ are the weighted sums of the recorded pounds of sales of each of the 
four species groups for those that target particular species and those that do not target any particular species. The measures are the mean across the two-month period of aggregate weight of catch sold to the United Fishing Agency. If an angler seeks a species group, then one of the indicator variables will equal one, and one term from the first sum will be picked out for the angler. For example, if angler $j$ seeks Billfish, $f=1$, and $\delta_{1 j}=1$, with $\delta_{n j}=0$ and $\delta_{f j}=0$ for $f>1$. If an angler does not seek a species, then $\delta_{n j}=1$, and the second sum will appear in the angler's utility function. The coefficients $\beta_{4 f}$ and $\beta_{5 f}, f=1, . ., 4$, capture the attraction of $q_{a f}$, which is the mean sale of species group $f$ from area $a$ for the period in which the trip took place.

The number of FADs at an ocean location provides additional information on the potential to catch fish. If past catches are known and they are good predictors of future catch, then in an ideal sense, FADs would provide no new information. But past information is imperfect and likely to be supplemented by other sources of news about catch, as well as characteristics of ocean locations. Hence FADs have a role beyond the catch itself.

The allocation of time and money costs (or out-of-pocket costs) is based on a model by Bockstael, Strand, and Hanemann (1987). Further, we assume that the decisions are made by the respondent, and ignore the costs for other participants on the boat. ${ }^{11}$ The costs of travel from home to ramp are transportation costs — that is, the vehicle costs of trailering a boat—plus the costs of time for individuals whose hours of work are flexible. Transportation costs are used only for individuals who cannot vary their hours of work. For the individuals who do not work or whose hours of work are not flexible, there are two categories: those who are retired $\left(\delta_{w j}=1\right)$ and those who work but do not have flexible hours $\left(\delta_{t j}=1\right)$. Consequently, the costs for an angler with flexible time will be $c_{r j}=$ transportation costs $+t_{r} \cdot v t_{j}$ where $v t_{j}$, the value of time for individual $j$, equals annual income divided by 2000 . This approximates the average hourly wage 
of the respondent. We expect $\beta_{2}$ and $\beta_{3}$ to be negative but have no clear priors on their relative magnitudes. The travel time from home to ramp is based on a regression of self-reported time as a function of distance, boat size, and ramp location. The travel costs on land will vary across individuals who might travel the same distance because they have to haul boats of different length. ${ }^{12}$ Likewise, travel costs in the water vary because boats of different length travel at different speeds. The water travel cost is based on self-reported costs per trip. This information is used to estimate a cost per mile traveled based on boat size. ${ }^{13}$

We assume that the stochastic element of equation 1 is distributed as a type I extreme value variate. We tested for generalized extreme value, but rejected the hypothesis that ramps and grid sites form a nest.

\section{Specification and Estimation}

The model we estimate makes each ramp-grid site into a unique alternative. We estimate a conditional logit model of ramp-grid choice such that the probability of choosing ramp-grid combination $r, a$, is:

$$
\operatorname{Pr}(r a \mid j)=\frac{\exp \left(v_{r a}(j)\right)}{\sum_{r^{\prime}=1}^{N_{r^{j}}} \sum_{a^{\prime}=1}^{M_{a j}} \exp \left(v_{r^{\prime} a^{\prime}}(j)\right)},
$$

where the number of ramps, $N_{r j}$, is the number of ramps in angler $j$ 's choice set, and $M_{a j}$ is the number of ocean areas in j's choice set. The maximum values of $N_{r j}$ and $M_{a j}$ are 13 and 34 . 
There are potentially 442 ramp-grid combinations $(13 \times 34)$ available to each angler. But angler choice sets are constrained both in the ramps they are able to use and the at-sea locations they seek. For anglers who moor their boat at a specific ramp, 408 of those ramp-grid combinations are ruled out as possible choices, and it is assumed that they choose from the 34 feasible grids, but have no choice of ramps. Anglers who trailer their boats are assumed to choose from among a subset of the 12 ramps and 34 grids (408 possible choices). If neither the angler nor angler's spouse are in the military, then the ramps at Hickam Harbor, Marine Corps Air Station, and Rainbow Bay are unavailable, as they are restricted to military only. Based on the idea anglers make rational decisions when deciding on their ramp-grid combination, we assume that they will only consider grid sites that lie within the half-circle created by drawing a line through the center of the island parallel to a tangent line drawn to each ramp. For example, if the ramp lies at the northern-most point of Oahu (i.e., Haleiwa), then only grid sites that lie north of a line drawn from east to west through the center of Oahu will be considered. This appears to be an accurate representation of anglers' behavior, as none of the interviewed anglers took trips that fell outside of the defined feasible area. ${ }^{14}$

\section{Results of Model Estimation}

The results of the conditional logit model of ramp-grid choice among Oahu anglers are reported in table 2. The model is estimated on the choice of the last trip of respondents in the sample of 468 fishermen. ${ }^{15}$ The results of this model are, for the most part, as we expected. Full travel $\operatorname{cost}\left(c_{r j}+c_{r a j}\right)$ has a negative, significant impact on the probability that a given ramp-grid is 
chosen, and all else equal, more distant sites provide less utility than closer sites. For fishermen who do not work for an hourly wage (they are either salaried or unemployed), travel time $\left(\mathrm{t}_{\mathrm{rj}} \delta_{w j}\right)$ has a negative but insignificant impact on the probability of site choice. For fishermen who are retired, travel time has a strong negative and significant effect on utility.

The marine variables also have the expected effects. Smaller boats find coastal grids more desirable than larger boats $\left(\beta_{11}>\beta_{10}\right)$ and distant grid sites are more desirable than coastal grid areas for anglers with large boats $\left(\beta_{10}<0\right)$. Increases in the catch sold of Billfish and Bottomfish for a given grid area significantly increase the probability that a particular grid will be chosen by anglers who target those species. However, the catch sold of Tuna and Other Pelagic does not have a significant effect. For anglers who do not target species, the catch of Bottomfish is the only significant catch variable (positive and significant). The mixed significance of the catch variables leads us to test their significance jointly. We test three hypotheses:

H1: All of the grid catch coefficients are zero;

H2: The four grid catch coefficients for anglers who target species are zero;

H3: The four grid catch coefficients for anglers who do not target species are zero.

As might be expected, the first hypothesis is rejected, with a calculated Chi-squared statistic of 18.6 , compared with a tabled value of 11.1 for the $97.5 \%$ level of significance. The second hypothesis is also rejected, with a calculated Chi-squared statistic of 12.7 . The nonseeking group has a p-value 0.13 , meaning that we fail to reject $\mathrm{H} 3$. This implies that anglers who do not seek species are not influenced by a joint increase in all catch variables. These 
results are easier to reconcile with recreational preferences than commercial goals, because we would expect fishermen motivated by financial rewards to respond more systematically to the historical catch of these species groups.

The other coefficient estimates accord with expectations. The size of the grid area has a very strong positive effect. Boats travel to larger sites, all else equal. Even though anglers do not explicitly choose grids on the basis of area, the fact that they choose among the finite number of sites implies that large areas are likely to be chosen more often, other things equal. The presence or number of FADs increases the likelihood of visits to a grid area, even when the recorded catch proxy has been accounted for. As the number of designated parking spaces increases at a ramp, the utility of visiting that ramp increases significantly. Two explanations for this are possible. First, the more designated parking spaces, the less likely the ramp will be congested with boat trailers, and second, the number of designated parking spaces can potentially capture unobservable quality attributes of particular ramps. Ramps that are exposed to trade winds are significantly less desirable during trade wind months, and the ramp at Waianae is significantly more desirable during yellowfin runs.

The empirical evidence supports the view of the small boat fishery as one in which anglers choose among ramps and ocean location based on distance, weather related variables, and past landings from the location. This evidence is consistent with motives that underlie commercial and recreational fishing, and combinations of the two. Fishermen choose ocean locations and would be affected by policies that change access or attributes of the locations. In the following sections we construct welfare measures for such changes. 


\section{Welfare Effects in the Small Boat Fishery}

An understanding of the benefits of angling — that is, the income equivalents - can aid in the formation of fishery management policies. Bockstael and McConnell (2007; chapter 7) give a complete development of welfare measurement for multiple site random utility models. All of the measures described below can be classified into one of two categories: loss of benefits due to loss of access to a subset of sites or loss/gain in benefits due to a change in the amenities of a site. $^{16}$ The welfare measures are all based on the assumption that the stochastic portion of preferences is additive and type I extreme value and that, for a given angler, the marginal utility of income is constant. Welfare measures are changes in income that their behavior reveals they would accept in compensation for changes in the fishery, including changes in access to sites.

Define $S_{j}$ as the set of all sites available to angler $j$ and $\mathrm{S}_{j}^{-}$as the set of sites available to angler $j$ after elimination of some subset of site. That is, they would be indifferent between the fishery without a change and the fishery with the change but the higher income. Then the value of lost access (also known as willingness to pay or equivalent income) to that subset of sites is:

$$
W T P_{j}(\text { access })=\frac{\ln \left(\sum_{r a \in S_{j}} e^{v_{r a}}\right)-\ln \left(\sum_{r a \in S_{j}^{-}} e^{v_{r a}}\right)}{\beta_{1}} .
$$

The change in willingness to pay for a change in amenities at one or more sites is measured as:

$$
W T P_{j}(\text { change in attributes }) \frac{\ln \left(\sum_{r a \in S_{j}} e^{v_{r a}^{0}}\right)-\ln \left(\sum_{r a \in S_{j}} e^{v_{r a}^{1}}\right)}{\beta_{1}},
$$


where $v_{r a}^{0}$ is the deterministic utility function from equation (2) evaluated at the current values of the right-hand side variables, and $v_{r a}^{1}$ is the deterministic utility function evaluated at the new values of the right-hand side variables. To convert to a money metric, the change in expected maximum utility is divided by the marginal utility of income $\left(\beta_{1}\right)$.

Much policy aimed at the regulation of fisheries involves access to areas at different times. In the ocean locations of the small boat fishery, there are several ways policies makers could influence fishing locations. One is simply by eliminating access. The particular alignment of locations that might have access limited would depend on the issues that the policy must address. As an example, we measure the welfare cost of closing the coastal grids - those sites that are closest to the shore.

The full sample average lost benefits (or willingness to pay to prevent closure) due to closure of all of the coastal grids is $\$ 10.61$ per angler per trip. While this measure of lost welfare may appear small, when aggregated across the median level of trips per year (approximately 12), the lost welfare is over $\$ 140$ per year per representative fisherman. Aggregated over the approximately 6,600 anglers, it implies a loss of about $\$ 0.9$ million. The mean lost value broken down by small/large boats and trailered versus moored boats appears in table $3{ }^{17}$

As expected, losses for anglers with moored boats are greater than losses incurred by those who trailer their boats. Small boats appear to have a smaller value for coastal grid sites than do larger boats. This might seem counterintuitive because it is expected that anglers with smaller boats will have a higher probability of choosing a coastal grid site relative to those with larger boats. This appears to be outweighed by the high value that owners of bigger boats place on a fishing trip. 
The presence and number of FADs in a grid area have a significant effect on the probability of choosing to fish in the area. Hence the loss of a FAD means a real economic loss. Table 4 shows the per-trip losses from the loss of FADs at the given grid area. These losses are underestimates because they assume that the aggregate catches are maintained in the absence of FADs, when in fact these catches are, in many cases, a consequence of the presence of FADs and would decline without them.

In many models of recreational fishing, one typically calculates welfare effects for changes in the attributes of shore sites or changes in the accessibility of shore sites. When the fishing is from shore, such as surf casting by recreational anglers, looking solely at shore sites makes sense. But when the fishing is from boats, the value of shore access is of less importance, especially when one can reach any of the fishing sites from any of the launch sites. Here we look at several dimensions of shore attributes, including access.

Table 5 reports the sample mean WTP of lost access per trip per angler for each of the 12 ramps on Oahu (i.e., the average lost welfare due to ramp closure for a single fishing trip). Note that these values are for trailered boats only. The second column reports the sample mean.

The values reported in each row represent the willingness to pay to prevent the closing of each ramp while keeping the remaining ramps open and available for launches and of course maintaining access to the ocean areas. The maximum average lost value due to ramp closure is for Waianae at $\$ 1.69$ per angler per trip. The individual specific values of lost access vary widely across ramps. Each ramp has a sample minimum lost value of access of zero if the ramp is not included in the choice set, and the maximum sample values of lost access vary from a minimum of $\$ 0.36$ per angler per trip for the Marine Corps Air Station to a maximum of $\$ 58.73$ per angler per trip for the ramp at Haleiwa. 
For purposes of understanding small boat fishing, we divide Oahu into four distinct geographic coastal regions: the north shore, the windward coast, the south shore, and the leeward coast. The north shore and the leeward coast each contain only one feasible boat ramp in the group of visited ramps: Haleiwa on the north shore and Waianae on the leeward. The lost value of closure of those coasts is therefore estimated as the value of closing those individual ramps. These values are $\$ 1.60$ and $\$ 1.69$, respectively. The south shore and the windward coast each have five visited ramps. The south shore ramps are Ala Wai, Hickam Harbor, Keehi, Rainbow Bay, and Hawaii Kai. The windward ramps are Heeia-Kea, Kahana, Kailua, Kaneohe, and Marine Corps Air Station. The values of lost access to the south shore ramps and windward coast ramps are $\$ 2.94$ and $\$ 6.80$, respectively.

It is also possible to value changes in site amenities using the random utility framework. For example, due to concerns about congestion, it might be useful to know what anglers are willing to pay for additional designated parking at ramps. This can be done on a per-ramp basis or an across-the-board increase at all ramps. We have chosen to report the latter. By simplifying equation (5), the value of a one unit change in one of the attributes across all sites can be found by dividing the parameter associated with that attribute by the marginal utility of income. For the case of parking spaces, the value per angler per trip of one additional parking space at each ramp can be found by dividing the parameter estimate associated with parking spaces ( $\beta_{9}=$ $0.011)$ by the utility of income $\left(-\beta_{1}=0.114\right)$, which yields a willingness to pay of $\$ 0.09$ per angler per trip for an additional parking space. An alternative value for additional parking can be found by increasing parking by $10 \%$ at each ramp. The willingness to pay per angler per trip for a $10 \%$ increase in parking at all ramps is $\$ 0.86$.

Taken in the context of a single trip per angler, the willingness to pay measures appear to 
be small for Hawaii. However, when taken in aggregate, the willingness to pay for access to ramps, ocean closures, parking spaces, or FADs can be substantial. For aggregation, the median number of trips taken by anglers over the past six-month period prior to the interview is six trips per angler (or 12 per year). Aggregating over the estimated 6,600 small boat anglers on Oahu leads to an estimate of 79,200 trips per year.

Multiplying by the average lost value per trip per angler due to ramp closure for Waianae (\$1.69) gives an aggregate welfare loss per year of $\$ 133,056$. The minimum average value of lost access for non-military sites occurs for the Kahana ramp. The aggregate lost value per year for closure of Kahana is $\$ 21,384$. These values are potentially lower than the value of ramp closures that might be found for mainland U.S. fisheries because substitution among ramps does not inhibit the ability of an angler to reach a particular grid to the same degree as it would on a linear coastline. Because close substitutes exist for each ramp and feasible grids accessible from each ramp overlap significantly, the lost value of the closure of a single ramp is moderate.

Multiplying the sample average willingness to pay for access to coastal grids ( $\$ 10.61)$ leads to an annual aggregate estimate of $\$ 840,312$ for the value of access to coastal grids. For management purposes, the willingness to pay for closure of coastal grids might be compared with gains for commercial fishing, if access to some grid areas were restricted to one group or another.

\section{Conclusion}

There is a considerable literature in fisheries that models the locational choices of commercial 
vessels. These models demonstrate that fishing firms make profit-maximizing decisions when they choose their ocean alternatives. The sequential way they make decisions posits the most important choices as location choices, with the selection of inputs dependent on these choices. In this article we have constructed a locational choice model for small boat fishermen that has some of the characteristics of the choices of large commercial enterprises, but without the extensive focus on the formation of expectations.

We demonstrate that locational choices by small boat anglers are made through choice of where to launch boats as well as the ocean location. The estimated model, a random utility model, can be used to calculate the welfare effects of restrictions on locational choices as well as changes in the attributes of alternatives, whether land-based (such as ramps) or ocean attributes (such as fish aggregating devices). This model, particular to Hawaii, shows the influence of species availability for the important species in Hawaii. Models such as this could be used in a variety of ways, such as demonstrating the benefits and costs of net bans or various types of spatial regulations. 


\section{Table 1}

Ramps and Their Characteristics

\begin{tabular}{|c|c|c|c|c|}
\hline $\begin{array}{l}\text { Ramp } \\
\text { Number }\end{array}$ & Ramp Name & Comments & $\begin{array}{c}\text { Parking } \\
\text { Spaces }\end{array}$ & $\begin{array}{c}\% \text { Recorded } \\
\text { Visits }\end{array}$ \\
\hline 1 & Ala Wai & & 19 & $3 \%$ \\
\hline 2 & Haleiwa $^{a}$ & & 60 & $9 \%$ \\
\hline 3 & Heeia-Kea $^{\mathrm{a}}$ & & 65 & $22 \%$ \\
\hline 4 & Hickam Harbor & Military Ramp & 12 & $2 \%$ \\
\hline 5 & Kahana $^{\mathrm{a}}$ & Launch Difficult & 28 & $1 \%$ \\
\hline 6 & Kailua $^{\mathrm{a}}$ & Launch Difficult & 25 & $2 \%$ \\
\hline 7 & Kaneohe & Private & 130 & $1 \%$ \\
\hline 8 & Keehi & & 59 & $15 \%$ \\
\hline 9 & Marine Corps Air Station ${ }^{\mathrm{a}}$ & Military Ramp & 30 & $1 \%$ \\
\hline 10 & Rainbow Bay & Military Ramp & 60 & $0.5 \%$ \\
\hline 11 & Hawaii Kai/Maunalua Bay & & 65 & $8 \%$ \\
\hline 12 & Waianae/Pokai Bay & & 180 & $24 \%$ \\
\hline 13 & Moored $^{b}$ & & & $12 \%$ \\
\hline
\end{tabular}

${ }^{\text {a }}$ Ramps are assumed to be exposed to trade winds from January through April.

${ }^{\mathrm{b}}$ This ramp is an artificial designation for all respondents whose boat was moored. 
Table 2

Parameter Estimates for Random Utility Model: Basic Model

\begin{tabular}{|c|c|c|c|}
\hline Parameter & Associated Variable & Parameter Estimate $^{a}$ & (Standard Error) \\
\hline$\beta_{1}$ & $c_{r j}+c_{r a j}$ & -0.114 & $(0.004)$ \\
\hline$\beta_{2}$ & $\delta_{w j} \cdot t_{r j}$ & -0.257 & $(0.408)$ \\
\hline$\beta_{3}$ & $\delta_{s j} \cdot t_{r j}$ & -1.760 & $(0.767)$ \\
\hline$\beta_{41}$ & $q_{a B I L L} \delta_{B I L L j}$ & 0.011 & $(0.005)$ \\
\hline$\beta_{42}$ & $q_{\text {авоттом }} \delta_{\text {воттомј }}$ & 0.017 & $(0.006)$ \\
\hline$\beta_{43}$ & $q_{a O T H E R} \delta_{\text {OTHERj }}$ & 0.002 & $(0.007)$ \\
\hline$\beta_{44}$ & $q_{\text {aTUNA }} \delta_{\text {TUNAj }}$ & 0.0009 & $(0.003)$ \\
\hline$\beta_{51}$ & $q_{a B I L L} \delta_{n j}$ & -0.0001 & $(0.001)$ \\
\hline$\beta_{52}$ & $q_{\text {авОттом }} \delta_{n j}$ & 0.007 & $(0.003)$ \\
\hline$\beta_{53}$ & $q_{a O T H E R} \delta_{n j}$ & -0.003 & $(0.004)$ \\
\hline$\beta_{54}$ & $q_{a T U N A} \delta_{n j}$ & 0.001 & $(0.001)$ \\
\hline$\beta_{6}$ & $K M_{a}^{2}$ & 0.0009 & $(.0002)$ \\
\hline$\beta_{7}$ & $W S_{r}$ & -0.752 & $(0.270)$ \\
\hline$\beta_{8}$ & $F_{a}$ & 0.829 & $(0.095)$ \\
\hline$\beta_{9}$ & $P_{r}$ & 0.011 & $(0.001)$ \\
\hline$\beta_{10}$ & $\delta_{b j} \cdot \delta_{c a}$ & -2.344 & $(0.291)$ \\
\hline$\beta_{11}$ & $\left(1-\delta_{b j}\right) \cdot \delta_{c a}$ & 0.611 & $(0.232)$ \\
\hline$\beta_{12}$ & $\delta_{W I r} \cdot \delta_{4 j}$ & 1.579 & $(0.404)$ \\
\hline$\beta_{13}$ & $\delta_{K I r}$ & -0.705 & $(0.325)$ \\
\hline$\beta_{14}$ & $\delta_{K A r}$ & -0.433 & $(0.488)$ \\
\hline
\end{tabular}

${ }^{\mathrm{a} B}$ Bold variables different from zero at the $99 \%$ level of confidence.

Table 3

WTP to Prevent Closure of Coastal HDAR's

\begin{tabular}{lcc}
\hline & Moored Boats & Trailered Boats \\
\cline { 2 - 3 } Small Boats $(<20$ feet $)$ & $\$ 13.44$ & $\$ 5.91$ \\
Large Boats $(\geq 20$ feet $)$ & $\$ 35.02$ & $\$ 14.37$ \\
\hline
\end{tabular}

Table 4 
Losses per Trip from Reductions in FADs

\begin{tabular}{lcccc}
\hline Grid Area & $\begin{array}{c}\text { Number } \\
\text { of FADs }\end{array}$ & $\begin{array}{c}\text { Percent of } \\
\text { Sample Trips }\end{array}$ & $\begin{array}{c}\text { Losses: } \\
\text { One FAD }\end{array}$ & $\begin{array}{c}\text { Losses: } \\
\text { All FADs }\end{array}$ \\
\hline 403 & 1 & 7.5 & $\$ 0.31$ & $\mathrm{a}$ \\
421 & 2 & 5.6 & 0.29 & $\$ 0.43$ \\
423 & 3 & 12.4 & 0.48 & 0.84 \\
424 & 1 & 3.4 & 0.12 & $\mathrm{a}$ \\
425 & 2 & 2.8 & 0.13 & 0.19 \\
426 & 2 & 3.9 & 0.14 & 0.20 \\
427 & 2 & 7.3 & 0.22 & 0.32 \\
428 & 1 & 2.4 & 0.13 & $\mathrm{a}$ \\
452 & 1 & 0.2 & 0.05 & $\mathrm{a}$ \\
\hline
\end{tabular}

${ }^{\mathrm{a}}$ When there is only one FAD, the losses are the same as for all FADs.

Table 5

Economic Losses from Ramp Closings, per Trip per Angler

\begin{tabular}{lc}
\hline Ramp & $\begin{array}{c}\text { Value of Lost Access } \\
N=413\end{array}$ \\
\hline Ala Wai & $\$ 0.94$ \\
Haleiwa & $\$ 1.60$ \\
Heeia-Kea & $\$ 1.59$ \\
Hickam Harbor & $\$ 0.05$ \\
Kahana & $\$ 0.27$ \\
Kailua & $\$ 1.83$ \\
Kaneohe & $\$ 1.19$ \\
Keehi & $\$ 0.89$ \\
Marine Corps Air Station & $\$ 0.01$ \\
Rainbow Bay & $\$ 0.07$ \\
Hawaii Kai/Maunalua Bay & $\$ 0.55$ \\
Waianae/Pokai Bay & $\$ 1.69$ \\
\hline
\end{tabular}




\section{References}

Bockstael, N. and K.E. McConnell. 2007 Valuing Environmental and Natural Resources with Revealed Preferences, Dordrecht, The Netherlands: Springer.

Bockstael, N., I. Strand and W.M. Hanemann. 1987. Time and the Recreation Demand Model. American Journal of Agricultural Economics 69:293-302.

Curtis, R. and R. Hicks. 2000. The Cost of Sea Turtle Protection: The Case of Hawaii's Longliners. American Journal of Agricultural Economics 82:1191-1197.

Haab, T. and K.E. McConnell. 2002. Valuing Environmental and Natural Resources: The Econometrics of Nonmarket Valuation. Northampton, MA: Edward Elgar.

Holland, D., J. Sanchirico, R. Curtis, and R. Hicks. 2005. An Introduction to Spatial Modeling in Fisheries Economics. Marine Resource Economics 19:1-6.

Holland, D. and J. Sutinen. 2000. Location Choice in New England Trawl Fisheries. Land Economics 76:133-149.

McConnell, K.E. and T.C. Haab 2001. "Small Boat Fishing in Hawaii: Choice and Economic Values.” JIMAR Contribution 01-336, Pelagic Fisheries Research Program, University of Hawaii, Manoa Joint Institute for Marine and Atmospheric Research.

Milon, J.W. 1988. Travel Cost Methods for Estimating the Recreational Use Benefits of Artificial Marine Habitats 20:87-101.

Mistiaen, J. and I. Strand. 2000. Location Choice of Commercial Fishermen with Heterogeneous Risk Preferences. American Journal of Agricultural Economics 82:1184-1190.

Smith, M. 2000. Spatial Search and Fishing Location Choice: Methodological Challenges of Empirical Modeling. American Journal of Agricultural Economics 82:1198-1206. 
.2005. State Dependence and Heterogeneity in Fishing Location Choice. Journal of Environmental Economics and Management 50:319-340. 


\section{ENDNOTES}

${ }^{1}$ We thank the Joint Institute for Marine and Atmospheric Science at the University of Hawaii for support and Sam Pooley for help with great local knowledge of the fishery. This work is not part of Marcia Hamilton's official duties for the Western Pacific Fishery Management Council and has not been reviewed or approved by the Council.

${ }^{2}$ See also Marine Resource Economics, first issue, 2005 for a series of papers on spatial issues in fisheries, including the introductory notes by Holland, Sanchirico, Curtis and Hicks.

${ }^{3}$ This restriction is detailed on the Hawaii Division of Aquatic Resources webpage http://www.hawaii.gov/dlnr/dar/fish_regs/oahu.htm last accessed on May 29, 2007. These regulations have been implemented since the research on the paper was completed.

${ }^{4}$ See for example the early study of the mid-Atlantic region by McConnell and Strand. This report can be obtained by emailing kmcconnell@arec.umd.edu.

${ }^{5}$ The survey was conducted by SMS, Inc., a survey firm in Honolulu.

${ }^{6}$ Any boat over six feet long and not documented through the Coast Guard must be registered with the State of Hawaii - the Division of Boating and Ocean Recreation in the Department of Land and Natural Resources (DLNR). From this list, the types of vessels that are typically not used in fishing - sailing, thrill craft, and motor vessels more than 65 feet in length-were eliminated.

${ }^{7}$ See the report by McConnell and Haab (2001) for complete details on the survey and tests of the representativeness of the sample. In general, the sample of respondents is representative of the population of anglers on Oahu.

${ }^{8}$ Survey design should ensure that the last trip is selected randomly. The phone survey was conducted in six, two-month waves. Calls for each wave were spread out over the two-month period.

${ }^{9}$ FADS are buoys anchored on the ocean floor. The buoys develop growth such as barnacles and grasses, attracting smaller fish which, in turn, attract bigger game fish.

${ }^{10}$ In addition to a simple control for trade wind exposure, we also attempted a more sophisticated approach involving the use of wind speed and direction data from NOAA weather sites. Wind speed at ramp $\mathrm{r}\left(\mathrm{WS}_{r}\right)$ is modeled:

$$
W S_{r}=M S \cdot\left(180-\left(W I^{d}-R A_{r}^{d}\right)\right) / 180,
$$

where MS = maximum of wind speed for the week; $W I^{d}=$ the angle of the wind in degrees deviation from north; $R A_{r}^{d}=$ the angle of a perpendicular to a line parallel to the shore, in degrees deviation from the north. Unfortunately, wind direction and speed do not appear to be significant factors in explaining ramp choice. (see McConnell and Haab (2001) for complete details).

${ }^{11}$ We thank a reviewer for questioning the effect of ignoring other participants. The impact is likely to be limited to underestimating the time costs. If this is like a random error, it is likely to attenuate the parameter estimate on the cost variable. The same direction of impact holds if the measured cost variable is some proportion of the true cost.

${ }^{12}$ By regressing the log of miles/minute on boat length, miles to ramp and a Waianae dummy variable, we find: Miles/Minute $=\exp (-1.58-0.188 * \ln ($ boat length $)+.54 * \ln ($ miles to ramp $)-$

$.21 *$ Waianae), where Waianae $=1$ if the visited ramp is Waianae.

${ }^{13} \mathrm{Cost}=\exp (-.678+1.37 * \ln ($ boat length $)+.24 * \ln ($ ocean miles traveled $))$. 
${ }^{14}$ This assumption makes estimation somewhat easier but has virtually no impact on the estimated coefficients. Virtually the same coefficients are estimated when we allow the choice set to be all possible grids.

${ }^{15}$ The interview was conducted by phone. The year-long survey was divided into six, twomonth sampling periods. The survey was initiated by a letter mailed to potential respondents. The survey completion rate was $31 \%$. However, many of the respondents did no boating or fishing. Only 3\% refused. A resurvey of potential subjects who could not be reached initially showed no significant difference in household characteristics from the sample we used.

${ }^{16}$ We could also calculate the value of introducing a new ramp if such a proposal were concrete.

${ }^{17}$ This estimate is likely to be a lower bound because the first trip lost is likely to be of less value than the last trip lost. This is a welfare effect that is not captured within random utility models. 